\title{
Manchu Intangible Cultural Heritage Protection Research Based on Digital Multimedia Technology
}

\author{
Junbo Dai \\ Library. Tong Hua Normal University \\ Jilin, China \\ e-mail: xiaodai@sina.com
}

\author{
Lishu Zhang \\ Library. Aviation University of Airforce \\ Jilin, China \\ e-mail: binger511@sina.com
}

\begin{abstract}
This paper expounds the current situation of Manchu intangible cultural heritage and the necessity to protect it by using the technology of multimedia. The details of Collecting, collating and making digital process of Manchu intangible cultural heritage by using multimedia technology are introduced in this thesis. The instrument, software use, sorting and classification of data types are also discussed here.
\end{abstract}

Keywords-Manchu; Intangible cultural heritage; Multimedia Technology

\section{INTRODUCTION}

Manchu is the third largest ethnic group in China which is second only to Zhuang nationality and the Hui minority . In the long history, Manchu people have created rich and colorful national culture which plays an important role in Chinese traditional culture. The convention following common practice describes intangible cultural heritage in the form of a list, as oral traditions and expressions- such as eoics, tales, and stories, performing arts - including music, song, dance, puppetry and theatre, social practices, ritauls and festive events, knowledge and practices concerning nature and universe- for example, folk medicine and folk astronomy, and traditional craftsmanship, as well as the sites and spaces in which culturally significant activities and events occur. A more generative, categorical definition is somewhat illusive. It is the culture people practise in their daily lives. But the impact of the modern civilization and the national culture in the process of continuous integration, Manchu cultural survival environment worsening.

Manchu is one of the 56 ethnic groups in China. It mainly lives in the northeast of china. Affected by some natural and social factors, the inheritance and development of Manchu culture has gradually declined. In recent years, our consciousness of protecting national culture is enhanced because it is highly valued by the government. Manchu have had two items proclaimed 'Masterpieces of Intangible Cultural Heritage of Humanity' by UNESCO and seven items proclaimed as Intangible Cultural Heritage by China. These Intangible Cultural Heritage includes oral traditions and expressions, performing arts, ritauls and festive events, ect.

Manchu's intangible cultural heritage is closely related to people's way of work and life. However, with the acceleration of globalization and modernization, dramatic changes have taken place in China's cultural ecology: intangible cultural heritage is confronted with great challenges and a lot of orally and behaviorally transmitted cultural heritage disappear one after another; a great deal of traditional craftsmanship is on the verge of extinction; a large number of precious objects and materials of historical and cultural values are destroyed, deserted or lost in foreign countries; arbitrary misuse and excessive exploitation of intangible cultural heritage occur from time to time. Therefore, the protection of intangible cultural heritage brooks no delay.

\section{How to PROTECT MANCHU INTANGIBLE CULTURAL HERITAGE BY MULTIMEDIA TECHNOLOGY}

\section{A. The concept of multimedia}

Multimedia is not a new term, it has been used for several decades and has many definitions associated with it. Broadly speaking, it refers to audio, video, graphics and text together. Multi-media database technology is a combination computer multi-media technology, network technology and traditional database technology. It is usually composed by display tier, view tier and physics tier. It supports integrated management and description of numbers, words, characters, graphics, images, audios and videos. It also supports multi-presenting forms of the uniformed media data and processing complicated media data. It can implement the functions of querying and searching multi-media data and also help users to deal with them logically and abstractly.

\section{B. The advantage of using multimedia}

Traditional culture, such as relics and works of art., we take the characters, graphics and objects of them to transmit history and civilization to public in the form of display. The intangible cultural heritage is invisible. It is difficult to display, so its protection should be different from the traditional tangible cultural heritage. The arrival of the internet age and the development of multimedia technology provide new way to solve this problem. For example, Manchu dance and song can be dynamically reproduced and displayed by multimedia technology. People can see and hear them vividly. Manchu folk craft which has nearly vanished can be shown again by multimedia technology. People can see the whole process of how ancient Manchu make it. Multimedia technology breaks through the limitation of space and distance so that the public can enjoy the beauty of the ancient art and creation. 


\section{The method and technology}

Manchu is an ancient minority; it leaves us great cultural heritages including all the material and spiritual heritages. The tangible heritage can be preserved in the form of cultural relics and museums; while the intangible heritage can only be preserved in personal ways. It usually exists in people's daily life, in their way of practice, performance and expression, so it is hard to record and inherit. The best way to collect and protect them is digitalized then and put them into internet platform. The multimedia technology that integrates text, animation, graphics, images, audio, video media and other media in the way of digital computer is the key technology of achieving the above functions.(Fig.1)

\section{The COLLECTION OF MANCHU INTANGIBLE CULTURAL HERITAGE DATA}

\section{A. Sound collection}

Music in ancient Manchu life was very popular. It includes the famous Manchu dance and song, Manchu opera and Shaman music. As to protect these cultural activities, the key issue is how to replay the behavior of human in activities. We solve the problem in two ways. First, by using camera or music pen, we video modern Manchu people when they sing and dance. Second, by motion capture technique we reconstruct ancient person in historical activities according to the descriptions and pictures in historical relics.

\section{B. Picture collection}

We collect many pictures about Manchu paper-cutting, embroidery, tapestry, clothing and architecture. As to protect these intangible heritages, the key issue is how to copy them vividly. Things like paper-cutting, cloth and architecture which are still exist in Manchu living region we take photos by digital camera. We also take photos about how Manchu people cooking and how they celebrating holidays. Things like historical relic which disappeared in history we get photos by $3 \mathrm{~d}$ scanning. We check books that contains these photos or we find some people who have these photos.3d scanner can obtain $3 \mathrm{~d}$ datum message by scanning object through laser beam. Then, the virtual object in the form of $3 \mathrm{~d}$ digital model can be set up.

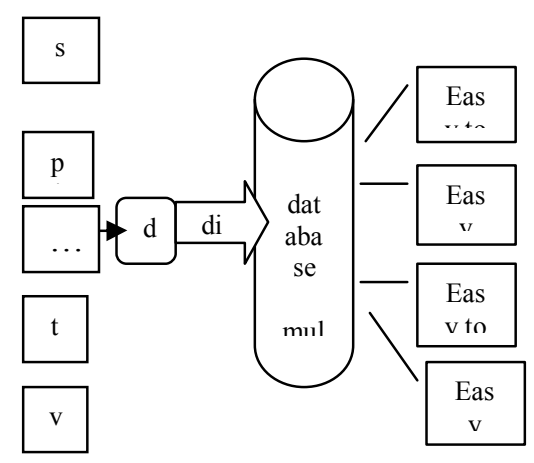

Fig. 1. The process of constructing Manchu intangible cultural heritage platform

\section{Text collection}

Manchu language is a branch of Altai phylum, a family of Tungus languages. This kind of language was written in a vertical direction with no space between the letters. As one of the most complex characters, Manchu character has many differences compared with Chinese and English, such as construction, spelling and composition of word. It is very difficult to collect texts of Manchu language. We find them in exhibition hall and collector's home. After digitalized, they become charming and vivid. In old days, these texts only exist in books with dust. Now they are in internet, with beautiful pictures and stories to explain them. Only in this way can Manchu texts be passed down. People living in modem society could like them and become inheritors of them.

\section{Data handling}

In the course of protecting intangible culture, different method should be chose according to specific condition and protected object owing to its universal inclusiveness.(TABLEI)

After we set up the platform, users can access it through network by passport word. By typing keywords, users can enquiry about information of Manchu intangible culture heritage. All texts, images, videos or audios can be displayed. Since given different operation authority, users can operate the information on line or download them as well. When new intangible cultural heritage is confirmed or some old one is disqualified, administrator can add or delete its record from the database. In addition, he can also add or delete the relevant texts, images, videos and audios describing them.(Fig2)

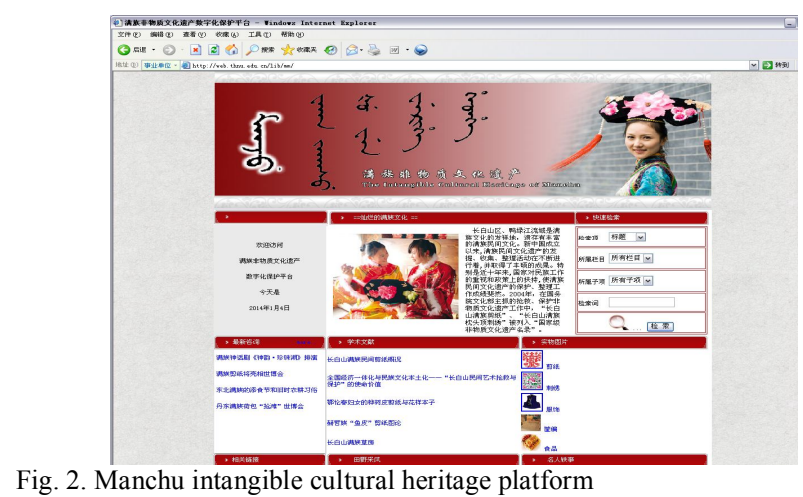

\section{DeTAILED DESCRIPTION}

\section{A. Embroidery and paper-cutting}

Embroidery is a unique language of Manchu people .It is a special carrier which is attached to its native culture, religion, ethics and customs. Manchu embroidery is fabulous in design and rich in pattern. It is rooted in people's understanding of their living environment and life. The embroidery tells us fairy tales, geography, history, religion and other cultural elements of Manchu.(Fig3)

First, we collect pictures of embroidery and paper-cutting and then digitalized them by using photoshop and fireworks. Then we insert them to the platform. Users can find them by typing key words.(Fig4) 


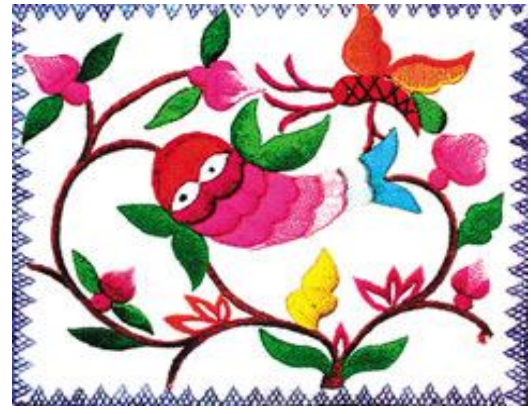

Fig. 3. Embroidery

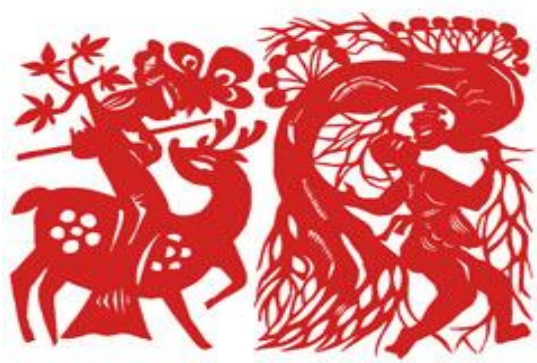

Fig. 4. Paper-cutting

There are also some videos in the platform. We find people who know how to do embroidery and paper-cutting .we photograph the whole process when they do it. Embroidery symbols reflect the geographical environment in which the ancient Manchu people lived, the original worship and customs. In addition to showing the high level of embroidery skills, every embroidery picture also helps to trace the history of social development.(Fig5)

\section{B. Manchu relics}

Manchu historical relics usually stored in museum. They are precious and forbidden to be touched. First we collect $3 \mathrm{~d}$ datum message by $3 \mathrm{~d}$ scanner. $3 \mathrm{~d}$ scanner can obtain $3 \mathrm{~d}$ datum message by scanning object through laser beam. Then, the virtual object in the form of $3 \mathrm{~d}$ digital model can be set up. Then we do texture recovery. Most cultural relics have endured physical and chemical encroachment for years, so their surface might have already been damaged and their colors have faded. We repair the texture by image processing software. We shoot the cultural relics to get $2 \mathrm{~d}$ texture and then divide the texture into color blocks by consulting original material object. (Fig6)

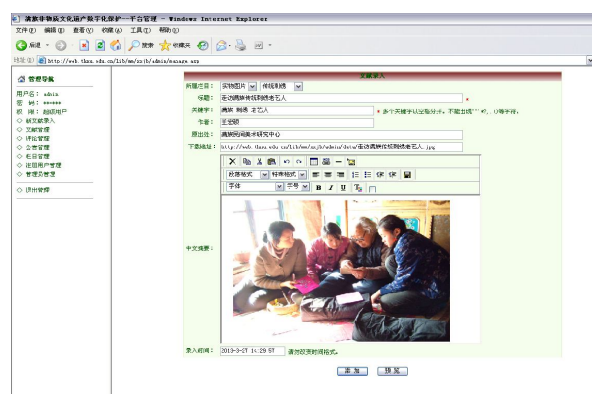

Fig. 5. Teaching video

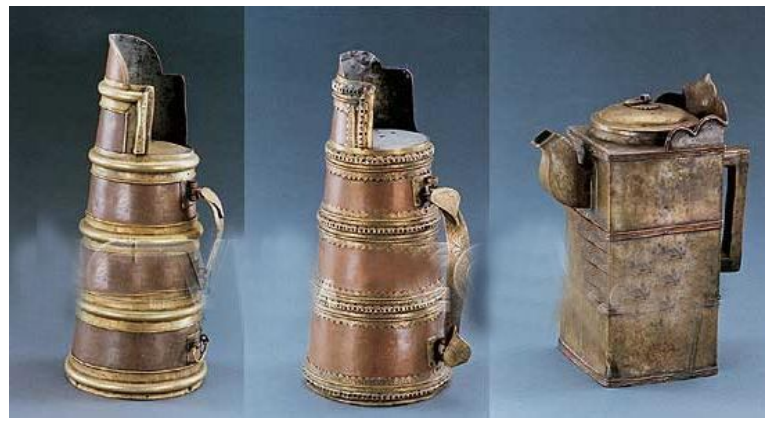

Fig. 6. Manchu kettle

\section{CONCLUSION}

The intangible material wealth is very important to a nation's development. The abundance of intangible culture, to a great extent, determines a nation's spiritual strength. It is the origin of traditional culture and the basis of national emotion concentration, self-recognition. The digital platform is an important information spreading place. First it can display digital collections. Visiting the platform, Users can see the whole world. The virtual reality technology can make the users are personally on the scene. Second it is an important way for distance education. It can help people understand the information in the platform through internet. Currently, each country is paying great attention to the protection of intangible cultural heritage. All kinds of technologies would be attempted and advanced adequately. The digital platform is a good way to do this with the development of computer and network technology.

\section{REFERENCES}

[1] Tweed.C,Sutherland.M,"Built Cultural Heritage and Sustainable Urban Development, " Landscape and Urban Planning, vol. 83, pp.62-69, No. 1,2007 .

[2] J.Y. Zheng,Z.L. Zhang,"Virtual Recovery of Excavated Relics, Computer Graphics and Applications, "Vol. 19, pp.6-11,No. 3, May/June 1999.

[3] L.Y. Qu, T.Lin, "Intangible Heritage and the Protection of Historical and Cultural City," Journal of Urban Studies, vol.14, pp.91-95, No.1,2007.

[4] Lawrence.S,Giles.L.C,and Bollacker.K,"Digital libraries and autonomous citation indexing." IEEE Computer, vol.32, pp. 6771,No.6,1999.

[5] A.Paepcke,M.Baldonado,C.-C.K.Chang,S.Cousins,andH.GarciaMolina."Using distribute objects to build the Stanford digital library in fobus." Computer, Vol. 32, pp.80-87,No.2,Feb1999.

[6] Flora.Mc.Martin,Ellen.Iverson,"The use of online digital resources and educational digital libraries in higher education, " International Journal on Digital Libraries, Vol.9, pp.65-79,No.1,2008 .

[7] WeiXia, "Digital library services: Perceptions and expectations of user communities and librarians in a New Zealand academic library, " Australia Academic and Research Libraries, Vol.34, pp.5670,No.1,2003.

[8] James Thong, WeiyinHong,and KarYanTam, "What leads to user acceptance of digital libraries?" Communications of the ACM , Vol. 47, pp.79-83,No.11,2004.

[9] KRIC, Korea Research Information Center,1998, http://www.kric.ac.kr. 
TABLE I. DATA HANDLING METHOD

\begin{tabular}{|c|c|c|}
\hline Data type & software & form \\
\hline text & ocr & $\begin{array}{l}\text { doc 、 caj 、 } \\
\text { kdh、pdf }\end{array}$ \\
\hline picture & Photoshop、 Fireworks & $\begin{array}{l}\text { bmp 、 jpg 、 } \\
\text { gif、 wmf }\end{array}$ \\
\hline sound & $\begin{array}{l}\text { Cool Edit Pro、Sound Forge、Wave Edit、 } \\
\text { Gold Wave }\end{array}$ & $\begin{array}{l}\text { wav 、 midi 、 } \\
\text { mp3、 wma }\end{array}$ \\
\hline video & $\begin{array}{l}\text { Adobe Premiere、 Sony Vegas 、 Campus } \\
\text { Edius、 }\end{array}$ & $\begin{aligned} & \text { avi } 、 \text { rm } 、 \\
& \text { mpeg、 dat } \text { mov } \\
&\end{aligned}$ \\
\hline flash & $\begin{array}{l}\text { 3D Studio 、 3D MAX、 Animator Studio 、 } \\
\text { Flash }\end{array}$ & $\begin{array}{l}\text { swf } 、 \max 、 \\
\text { 3ds、avi、mov }\end{array}$ \\
\hline
\end{tabular}

